\begin{tabular}{c} 
TAP CHÍ KHOA HỌC ĐẠI HỌC TÂN TRÀO \\
ISSN: 2354 - 1431 \\
\hline
\end{tabular}

\title{
Chính sách ngôn ngữ của Singapore
}

\author{
Nguyễn Thị Nhu ${ }^{a} *$ \\ ${ }^{a}$ Tạp chí Cộng sản \\ *Email: phongnhu1977tccs@gmail.com
}

\section{Thông tin bài viết}

Ngày nhận bài:

18/03/2018

Ngày duyệt đăng:

$12 / 6 / 2018$

\section{Tù khoá:}

Singapore, chính sách ngôn ngũu, giải pháp.

\section{Tóm tắt}

Singapore là quốc gia đa ngôn ngữ, vì thế chính sách về ngôn ngữ gắn liền với các kế hoạch của chính phủ. Hiện nay, Chính phủ Singapore duy trì đa dạng ngôn ngữ, tác động đến việc sử dụng ngôn ngữ trong cộng đồng nói các ngôn ngữ đó thông qua hệ thống giáo dục. Bài viết giới thiệu, tổng thuật về chính sách ngôn ngữ của Singapore và tập trung làm rõ ba vấn đề: (1). Cảnh huống ngôn ngữ và chính sách ngôn ngữ của Singapore; (2). Một số nội dung cơ bản về chính sách ngôn ngữ ở Singapore; (3). Những vấn đề đặt ra trong quá trình thực hiện chính sách ngôn ngữ và giải pháp của chính phủ Singapore.
Vốn là xã hội di cư ngay từ khởi đầu, Singapore là xã hội đa văn hóa từ trước khi nó trở thành quốc gia hiện đại và độc lập. Là nơi sinh sống của rất nhiều nhóm người thuộc các dân tộc, văn hóa, tôn giáo khác nhau, quốc gia này cũng trở thành quốc gia đa ngôn ngữ. Chính vì vậy, ở Singapore, chính sách ngôn ngữ gắn liền với các kế hoạch của chính phủ. Trong cách tiếp cận theo trục dọc, Chính phủ Singapore tác động đến việc sử dụng ngôn ngữ trong cộng đồng thông qua hệ thống giáo dục ${ }^{1}$. Đáp ứng mục tiêu đặt ra của chính phủ, chính sách ngôn ngữ của Singapore tạo điều kiện giao tiếp hiệu quả trong các cộng đồng đa tộc người, duy trì một xã hội đoàn kết trong đa dạng, giúp Singapore nhanh chóng hội nhập với thế giới nhưng cũng tạo ra những lỗ hổng chưa thể lấp đầy giữa chính sách và thực tiễn.

\section{Cảnh huống ngôn ngữ và chính sách ngôn ngữ của Singapore}

Singapore là một quốc gia đa tộc người với dân số khoảng 5.758.425 triệu người ${ }^{2}$, trong đó có khoảng $76,8 \%$ người gốc Hoa, 13,9\% người Mã Lai, 7,9\% gốc

${ }^{1}$ Kaplan B., Robert, and Richard B. Baldauf Jr.(1997), Language Planning from Practice to Theory.Clevedon: Multilingual Matters ltd., 1997

${ }^{2}$ Worldometer 2017, http://www.worldometers.info/worldpopulation/singapore-population/ truy cập ngày 04/2/2018
Ân Độ, trong khi $1,4 \%$ là các tộc người khác ${ }^{3}$. Các cuộc liên hôn và sự chung sống hòa hợp giữa những dân tộc khác nhau đã dệt nên một bức tranh văn hóa đầy màu sắc, hình thành nên xã hội Singapore đa dạng nhiều mặt, để lại cho đảo quốc này kho tàng ngôn ngữ phong phú. Ngôn ngữ ở Singapore thậm chí ngày càng đa dạng bởi trong các nhóm ngôn ngữ chính ở đây như tiếng phổ thông Hán ngữ, Anh, Mã Lai, Tamil lại có sự biến thể, mở rộng thành nhiều ngôn ngữ địa phương khác. Chẳng hạn, người Hoa ở đây không chỉ nói tiếng Trung phổ thông (còn được gọi là tiếng phổ thông Hán ngữ), họ còn nói tiếng Mân Nam, Triều Châu, Quảng Đông, Khách Gia, Hải Nam, Phúc Châu... Hay người Ấn Độ, ngay từ khi đến Singapore giao thương, họ lại đến từ các bang khác nhau của Ấn Độ, trong khi mỗi bang tại Ấn Đô lại có một ngôn ngữ khác nhau. Bởi thế, những người Ấn Độ đến Singapore ngoài nói tiếng Tamil, Hindi là chính, họ còn nói tiếng Telugu, Kannada, Panjabi, Gujarati, Sindhi, Urdu... Các biến thể ngôn ngữ của Melayu tại Singapore dù số lượng ít hơn tiếng Trung và Ân Độ, nhưng cũng bao gồm các ngôn ngữ chính là Melayu (68\%), Java (18\%), Boyanese (11\%), và "những ngôn

${ }^{3}$ Lionel Wee (2010), 'Burdens' and 'handicaps' in Singapore Language Policy: on the limits of language management', p. 98, languagee Policy, volume 9, issue 2. 
ngữ khác" (3\%). Ngay cả tiếng Anh ở đây cũng có biến thể "bồi" của nó được gọi là Singlish. Ngoài ra còn rất nhiều ngôn ngữ của tộc người thiểu số tại Singapore góp phần làm đa dạng hệ thống ngôn ngữ của quốc gia này.

Xuất phát từ bối cảnh trên, có hai quan điểm về ngôn ngữ nổi bật được Chính phủ Singapore thông qua:

- Quốc tế hóa: Quan điểm này đòi hỏi thông qua một ngôn ngữ không phải là bản địa như một ngôn ngữ chính thức. Chính phủ Singapore đã thông qua việc sử dụng tiếng Anh bên cạnh các ngôn ngữ bản địa của Singapore.

- Đa nguyên ngôn ngũ̃: Đòi hỏi công nhận và hỗ trợ sự đồng tồn tại của nhiều ngôn ngữ trong xã hội.

Từ đây, nhà nước tiến hành phân loại dân cư và chia thành từng nhóm cụ thể để kiểm soát tính đa dạng tộc người và ngôn ngữ của Singapore. Theo đó, các tộc người chính và thành viên bao hàm được xác định thông qua sự sát nhập ngôn ngữ trong lịch sử, tập quán văn hóa và đặc trưng chủng tộc. Singapore công nhận nhóm người gốc Hoa, Mã Lai, gốc Ân Độ và lai Á-Âu như "các chủng tộc sáng lập" đã góp sức đáng kể giành độc lập nước nhà. Trên thực tế, ba chủng tộc sáng lập đầu tiên có đủ số lượng thành viên để xem như những cộng đồng có quyền lợi riêng, trong khi chủng tộc lai Á-Âu được xem là người gốc "khác" vì số lượng quá nhỏ.

Trên cơ sở phân loại theo tộc người, chính phủ đưa ra chính sách song ngữ gồm tiếng Anh và tiếng mẹ đẻ áp dụng cho các chủng tộc này. Trong đó, tiếng mẹ đẻ được chỉ định chính thức cho từng tộc người cụ thể, là bản sắc văn hóa tộc người đó. Cụ thể, tiếng phổ thông Hán ngữ cho người gốc Hoa, tiếng Melayu cho người Mã Lai và tiếng Tamil cho người gốc Ấn Độ. Tuy người gốc Á-Âu thường sử dụng tiếng Anh nhưng chính phủ không chấp thuận tiếng Anh là tiếng mẹ đẻ của họ, vì lý do muốn giữ tiếng Anh như nhân tố trung lập giữa các chủng tộc ${ }^{4}$. Theo đó, Hiến pháp Singapore quy định trong điều 153A công nhận tiếng Melayu, phổ thông Hán ngũ̃, Tamil và tiếng Anh là bốn ngôn ngữ chính thức và xác nhận tiếng Anh là ngôn ngữ hành chính của đất nước. Trên quan điểm quốc tế hóa và đa nguyên ngôn ngữ, chính sách song ngữ được thực hiện, thống nhất 4 luồng giáo dục

${ }^{4}$ Lim, L., A. Pakir \& L. Wee, "English in Singapore: Policies and Prospects", in Lim, L., A. Pakir \& L. Wee, Ed., English in Singapore: Modernity and Management, Singapore: NUS Press, 2010, pp. 3-10
Melayu, phổ thông Hán ngữ, Anh, Tamil, giáo dục song ngữ được Bộ Giáo dục Singapore cung cấp.

Theo chính sách song ngữ, Bộ Giáo dục bảo đảm rằng, học sinh tiểu học và trung học nhất thiết phải học song ngữ - tất cả học sinh được giáo dục bằng tiếng Anh là ngôn ngữ đầu tiên và phải học tiếng mẹ đẻ của họ như một ngôn ngữ thứ hai ${ }^{5}$. Học một ngôn ngữ thứ hai là bắt buộc ở các trường tiểu học từ năm 1960 và trường trung học kể từ năm $1966^{6}$. Học sinh được dạy phổ thông Hán ngữ, Melayu hoặc Tamil tùy thuộc vào dân tộc của cha mình.

\section{Một số nội dung cơ bản về chính sách ngôn ngũ̃ ở Singapore}

\section{1. Động lục của chính sách ngôn ngũ}

Trong khi tiếng Anh là ngôn ngữ cốt lõi được giảng dạy trong các trường công lập thì tiếng mẹ đẻ được dạy hàng tuần. Như vậy, nếu "tiếng mẹ đẻ" thường tương ứng với ngôn ngữ thứ nhất ở các nước, ở Singapore, Bộ Giáo dục lại đề cập đến nó như là "ngôn ngữ dân tộc" hoặc ngôn ngữ thứ hai ${ }^{7}$. Kế hoạch ngôn ngữ của Singapore còn được gọi là kế hoạch ngoại sinh, qua đó ngôn ngữ nước ngoài đóng vai trò là ngôn ngữ chính của truyền thông so với các ngôn ngữ bản địa trong nước. Hệ thống giáo dục nhằm mục đích tạo ra một lực lượng lao động song ngữ bằng tiếng Anh và tiếng phổ thông Hán ngữ / Melayu / Tamil ${ }^{8}$.

Với chính sách song ngữ, Chính phủ khuyến khích người dân Singapore thông thạo cả tiếng Anh lẫn tiếng mẹ đẻ. Bắt buộc học tiếng Anh ở tất cả các trường học là nỗ lực hướng tới một ngôn ngữ chung để tất cả những sắc tộc trên đất nước này có thể giao tiếp và hiểu nhau, nhằm thúc đẩy sự hiểu biết tốt hơn giữa các dân tộc tại Singapore, phù hợp với nỗ lực xây dựng đất nước. Bên cạnh đó, do tầm quan trọng của tiếng Anh với tư cách một ngôn ngữ quốc tế, người Singapore bắt đầu chú ý hơn đến việc học tiếng Anh mà tập trung ít hơn vào việc học tiếng mẹ đẻ. Điều này cũng kéo theo sự lo ngại rất thực tế nữa là Singapore phải đối mặt với ảnh hưởng của văn hóa phương Tây ngày càng tăng - mối đe dọa tiềm ẩn đối

${ }^{5}$ Goh, K. S. et al. (1979), Report on the Ministry of Education 1978. Singapore: Ministry of Education

${ }^{6} \mathrm{Xem}$ Language education in Singapore.

${ }^{7}$ Goh, K. S. et al. (1979), Report on the Ministry of Education 1978, Singapore: Ministry of Education.

${ }^{8}$ Goh, K. S. et al. (1979), Report on the Ministry of Education 1978, Singapore: Ministry of Education. 
với việc dân tộc hóa. Bởi vậy, duy trì chính sách tiếng Anh là ngôn ngữ chung nhưng vẫn cần phải giữ lại được những đặc tính tốt nhất trong văn hóa của mỗi sắc tộc. Chính sách song ngữ vì thế được ban hành còn để bảo vệ bản sắc và các giá trị châu Á trong các sắc tộc ở Singapore. Cùng với tiếng Anh, Chính phủ Singapore thúc đẩy sử dụng tiếng phổ thông Hán ngữ, Melayu và Tamil nhằm ngăn chặn sự xói mòn của văn hóa và di sản của ba dân tộc chính ${ }^{9}$.

Là một xã hội đa tộc người, Singapore đưa ra chính sách "chủng tộc hòa đồng", công bằng, bình đẳng cho mọi tộc người. Việc sử dụng bốn ngôn ngữ chính thức như trên là một phần của chính sách này nhằm tạo ra sự hài hòa tộc người với quan niệm rằng ngôn ngữ dân tộc là "người vận chuyển văn hoá", trong khi tiếng Anh là "ngôn ngữ thương mại", bởi thực tế tiếng Anh từng là ngôn ngữ của chính quyền thuộc địa và cũng là tiếng mẹ đẻ của một số ít người Singapore vào thời điểm thực hiện chính sách ${ }^{10}$. Với tiếng Anh là ngôn ngữ trung lập, không một dân tộc nào được thiên vị hơn, bảo đảm việc phân phối các lợi thế kinh tế công bằng cho nhóm các dân tộc thiểu số; mặt khác, các nền văn hóa đều được bảo tồn. Ý tưởng đằng sau chính sách này là hướng tất cả các ngôn ngữ theo chuẩn và vì thế có uy tín ngang nhau để dẫn đến việc các diễn giả của từng ngôn ngữ được đối xử bình đẳng ${ }^{11}$.

\subsection{Kế hoạch hóa vị thế ngôn ngũ}

Như vậy, chính sách ngôn ngữ ở Singapore tồn tại trên nền tảng của sự đa dạng, sự đa dạng có mặt ở đây kể từ khi Singapore thành lập, được thể hiện rõ ràng cả về thành phần dân tộc và ngôn ngữ. Cách Singapore quản lý sự đa dạng ngôn ngữ cho thấy, một trong những thay đổi rõ rệt nhất trong bối cảnh ngôn ngữ của Singapore sau độc lập là việc thúc đẩy vị thế của tiếng Anh. Điều này được thực hiện bằng việc xác nhận tiếng Anh là ngôn ngữ hành chính của đất nước, phân bổ nguồn lực để phát triển tiếng Anh trong các lĩnh vực chức năng khác nhau như chính phủ, luật pháp, kinh doanh, quản trị, và đặc biệt là môi trường giảng dạy trong các trường học - mặc dù thời gian đó lẽ ra phải được dành cho việc học ngôn ngữ mẹ đẻ.

${ }^{9}$ Mohamed, S. (2005) Planning for Malay Language in Education. Centre for Research in Pedagogy and Practice, Nanyang Institute of Education, Singapore.

${ }^{10}$ Clammer, John (1998), Race and State in Independent Singapore 1965-1990, Brookfield: Ashgate. pp. 40-42. ISBN 978-1-84014-029-3.

${ }^{11}$ Vasil, Raj (1995),. Asianing Singapore: The PAP's Management of Ethnicity, Singapore: Heinemann Asia, pp. 64-66.
Một chiến dịch nói tiếng Anh tốt được Chính phủ Singapore khởi xướng với Phong trào Nói tiếng Anh tốt (SGEM -Speak Good English Movement) ${ }^{12}$ nhằm "khuyến khích người Singapore nói đúng ngữ pháp tiếng Anh chuẩn trên toàn cầu" "13, kêu gọi công dân xóa bỏ Singlish ${ }^{14}$ - một dạng tiếng Anh lai tạp với tiếng Trung và tiếng Melayu được sử dụng trong giao tiếp hằng ngày giữa người Singapore với nhau, được sử dụng rộng rãi ở Singapore ${ }^{15}$ nhưng hầu như người nước ngoài nói tiếng Anh không thể hiểu nổi. Cho rằng Singlish cản trở việc học tiếng Anh "phù hợp", tuân theo chính sách của chính phủ, các trường học đẩy mạnh tiếng Anh chuẩn, giảm thiểu việc sử dụng Singlish trong lớp học ${ }^{16}$. Cơ quan Phát triển Truyền thông - một ủy ban pháp định của chính phủ, yêu cầu giới truyền thông Singapore sử dụng Singlish ít nhất có thể, tuyên bố nó chỉ phù hợp với “các cuộc phỏng vấn, nơi mà người phỏng vấn chỉ biết nói Singlish" 17 .

Chính phủ cũng đưa ra giải thưởng "Inspiring teacher of English - Giáo viên tiếng Anh truyền cảm hứng" ${ }^{\text {"18 }}$. Năm 2013, Học viện Anh ngữ Singapore được thành lập nhằm mục đích trước hết là giảng dạy Tiếng Anh chuẩn cho người Singapore, sau đó hướng tới trở thành trung tâm dạy Tiếng Anh cho toàn châu Á.

Vị thế của tiếng Phổ thông Hán ngữ cũng được nâng cao khi Chính phủ Singapore chỉ định đó là tiếng mẹ đẻ của người dân Singapore gốc Trung Quốc, bắt buộc người Hoa ở Singapore học tiếng phổ thông Hán ngữ như tiếng mẹ đẻ trong các trường học. Theo đó, Singapore khuyến khích hình thức chuẩn hóa duy nhất

\footnotetext{
${ }^{12}$ 'Lionen Wee(2010), Burdens' and 'handicaps' in Singapore Language Policy: on the limits of language management', p. 99.

${ }^{13}$ Speak Good English Movement - What We Do Archived 30 August 2011 at the Wayback Machine. Retrieved 18 November 2010 .

14 "Singapore attack on 'Singlish"'. BBC News. 5 April 2001. Retrieved 13 November2011.

${ }^{15}$ Tien. Adrian (2010), Chinese-based lexicon in Singapore English, and Singapore-Chinese culture $(P D F)$, archived from the original $(P D F)$. Cũng xem Leimgruber, Jakob, From Post-Creole Continuum to Diglossia: The Case of Singapore English (PDF), University of Oxford.

${ }^{16}$ Foley, Joseph (2001) "Is English a first or second language in Singapore?", in Vincent B. Y. Ooi (ed.), Evolving Identities: The English Language in Singapore and Malaysia, Singapore: Times Academic Press, pp. 12-32. Cũng xem Deterding, David (1998) 'Approaches to Diglossia in the Classroom: The Middle Way. REACT, 2, 18-23.' (on-line version).

${ }^{17} \mathrm{http} / / /$ www.mda.gov.sg/wms.file/mobj/mobj.612.fta_tv_prog_cod e.pdf.

${ }^{18}$ Speak Good English Movement website, có nghĩa là Giảng viên tiếng Anh truyền cảm hứng.
} 
của tiếng phổ thông Hán ngữ, không khuyến khích việc sử dụng các phương ngữ trong cộng đồng gốc Hoa Singapore như tiếng Quảng Đông, Triều Châu và Mân Nam. Tháng 9-1979, Chính phủ phát động chiến dịch tiếng phổ thông Hán ngữ với mục tiêu đơn giản hóa môi trường ngôn ngữ, cải thiện giao tiếp giữa những người Singapore gốc Hoa từ các nhóm phương ngữ khác nhau, tạo ra một môi trường nói tiếng phổ thông Hán ngữ ủng hộ các chính sách giáo dục song ngữ quốc gia. Áp dụng tiếng phổ thông Hán ngữ chuẩn, chính phủ vừa thống nhất người gốc Hoa bằng một ngôn ngữ chung, vừa để tạo điều kiện giao tiếp với người Trung Quốc ở bên ngoài Singapore. Kể từ khi phát động, chiến dịch đã thúc đẩy việc sử dụng tiếng phổ thông Hán ngữ trong cộng đồng gốc Hoa thông qua nhiều hoạt động quảng bá và tiếp cận khác nhau, thành công trong việc thay đổi thói quen ngôn ngữ của người Singapore gốc Hoa.

\subsection{Kết quả của việc thục hiện chính sách ngôn ngứ}

Việc thể chế hóa tích cực một vài ngôn ngữ hơn các ngôn ngữ khác và sự thực thi chủ động những chính sách ngôn ngữ có tác động lâu dài và trước mắt lên việc sử dụng ngôn ngữ trong xã hội Singapore.

Bảng 1: Các ngôn ngữ được sử dụng nhiều nhất ở Singapore (đơn vị \%)

\begin{tabular}{|c|c|c|c|c|c|}
\hline & Tiếng Anh & $\begin{array}{c}\text { Tiếng phố } \\
\text { thông Hán } \\
\text { ngữ }\end{array}$ & $\begin{array}{c}\text { Tiếng } \\
\text { Hán phương } \\
\text { ngữ }\end{array}$ & Tiéng Tamil & $\begin{array}{c}\text { Tiếng } \\
\text { Melayu }\end{array}$ \\
\hline 1957 & $1.8 \%$ & $0.1 \%$ & $74.4 \%$ & $5.2 \%$ & $13.5 \%$ \\
\hline 1980 & $11.6 \%$ & $10.2 \%$ & $59.5 \%$ & $3.1 \%$ & $13.9 \%$ \\
\hline 1990 & $18.8 \%$ & $23.7 \%$ & $39.6 \%$ & $2.9 \%$ & $14.3 \%$ \\
\hline 2000 & $23 \%$ & $35 \%$ & $23.8 \%$ & $3.2 \%$ & $14.1 \%$ \\
\hline 2010 & $32.3 \%$ & $35.6 \%$ & $14.3 \%$ & $3.2 \%$ & $12.2 \%$ \\
\hline
\end{tabular}

Sources:Kuo (1980), Lau (1993), Department of Statistics $(2001 ; 2006 ; 2011)$.

Bảng số liệu trên cho thấy, hiện ở Singapore có rất nhiều ngôn ngữ được sử dụng, số lượng người sử dụng tiếng Anh, tiếng phổ thông Hán ngữ là đông nhất và tăng liên tục. Trong khi đó các phương ngữ Hán như Mân Nam, Quảng Đông và Triều Châu đã giảm đáng kể trong năm thập kỷ qua. Ví dụ: nhóm ngôn ngữ tiếng Anh tăng lên rất nhiều từ $1.8 \%$ năm 1957 lên $32.3 \%$ năm 2010. Hay tiếng phổ thông Hán ngữ tăng từ $0.1 \%$ năm 1957 lên 35.6\% năm 2010. Còn nhóm ngôn ngữ phương ngữ Hán giảm rất nhanh từ 74.4\% năm 1957 xuống còn $14.3 \%$ năm 2010 .
Bảng 2: So sánh việc sử dụng Tiếng Anh và tiếng mẹ đẻ ở Singapore qua các năm (đơn vị \%)

\begin{tabular}{|c|c|c|c|c|c|}
\hline $\begin{array}{c}\text { Nhớm tồc } \\
\text { ngươi }\end{array}$ & Ngón ngo & 1980 & 1990 & 2000 & 2010 \\
\hline \multirow{3}{*}{ Ngañì Hoa } & Tièng Anh & $10.2 \%$ & $21.4 \%$ & $23.9 \%$ & $32.6 \%$ \\
\hline & $\begin{array}{c}\text { Tiéng phỏ } \\
\text { thờng Hín } \\
\text { ngò }\end{array}$ & $13.1 \%$ & $30 \%$ & $45.1 \%$ & $47.7 \%$ \\
\hline & $\begin{array}{l}\text { Tiéng fin } \\
\text { phưong ngù }\end{array}$ & $76.2 \%$ & $48.2 \%$ & $30.7 \%$ & $19.2 \%$ \\
\hline \multirow[b]{2}{*}{ Ma Lai } & Tiềng Anh & $2.3 \%$ & $5.7 \%$ & $7.9 \%$ & $17 \%$ \\
\hline & $\begin{array}{l}\text { Tiéng } \\
\text { Melayu }\end{array}$ & $96.7 \%$ & $94.1 \%$ & $91.6 \%$ & $82.6 \%$ \\
\hline \multirow{4}{*}{ 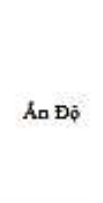 } & Tiếng Anh & $24.3 \%$ & $34.3 \%$ & $35.6 \%$ & $41.6 \%$ \\
\hline & Tiéng Tamil & $52.2 \%$ & $43.5 \%$ & $42.9 \%$ & $36.6 \%$ \\
\hline & $\begin{array}{l}\text { Tiéng } \\
\text { Melayu }\end{array}$ & $8.6 \%$ & $14.1 \%$ & $11.6 \%$ & $7.9 \%$ \\
\hline & $\begin{array}{l}\text { Cde agón } \\
\text { nga khảe }\end{array}$ & $14.9 \%$ & $8.1 \%$ & $9.2 \%$ & $13.2 \%$ \\
\hline
\end{tabular}

Sources: Lau (1993), Department of Statistics $(2005 ; 2011)$.

Qua bảng số liệu 2, ta nhận thấy, trong từng nhóm tộc người cũng có sự đa dạng về ngôn ngữ. Vấn đề đáng lưu ý ở đây là hiện tượng song ngữ. Tất cả các nhóm tộc người ngoài việc sử dụng ngôn ngữ mẹ đẻ ra còn sử dung ngôn ngữ thứ hai là tiếng Anh. Tiếng Anh được phổ biến với số lượng người sử dụng tăng qua các năm. Trong khi đó, các ngôn ngữ mẹ đẻ khác có sự biến động khác nhau giữa các nhóm. Ví dụ nhóm tộc người Hoa, số người sử dụng tiếng Anh tăng từ 10.2\% năm 1980 lên 32.6\% năm 2010. Số người sử dụng tiếng phổ thông Hán ngữ tăng từ 13.1\% năm 1980 lên 47.7\% năm 2010, trong khi số người sử dụng tiếng Hán phương ngữ khác giảm đáng kể từ $76.2 \%$ xuống chỉ còn $19.2 \%$.

Bảng 3:

\begin{tabular}{|} 
Ngôn ngđ̛ được nói nhiều nhất ở nhà (\%) $\mathbf{1}^{19}$ \\
\begin{tabular}{|l|c|c|c|c|}
\hline Ngôn ngđ̛ & 1990 & $\mathbf{2 0 0 0}$ & $\mathbf{2 0 1 0}$ & $\mathbf{2 0 1 5 ^ { 2 0 }}$ \\
\hline Tiếng Anh & 18,8 & 23,0 & 32,3 & 36,9 \\
\hline Phổ thông Hán ngữ & 23,7 & 35,0 & 35,6 & 34,9 \\
\hline Phương ngữ Hán & & 23,8 & 14,3 & 12,2 \\
\hline Tiếng Melayu & 14,3 & 14,1 & 12,2 & 10,7 \\
\hline Tiếng Tamil & 2,9 & 3.2 & 3,3 & 3,3 \\
\hline Ngôn ngữ khác & & 0,9 & 2.3 & 2.0 \\
\hline
\end{tabular}
\end{tabular}

Theo bảng 3, tỷ lệ số người Singapore sử dụng tiếng Anh ở nhà tăng đều từ 18,8\% năm 1990 lên $36,9 \%$ năm 2015, vượt qua cả tỷ lệ sử dụng tiếng phổ thông Hán ngữ là 34,9\%.

Như vậy, chính sách ngôn ngữ ở Singapore, đặc biệt là chính sách song ngữ ra đời đã đem lại những kết quả đáng khích lệ về nhiều mặt, về cơ bản đáp ứng mục tiêu đặt ra của chính phủ: 
Thư nhất, tiếng Anh được phát triển, đóng vai trò quan trọng trong hệ thống ngôn ngữ ở Singapore, dần chiếm ưu thế trong xã hội trước sự thông dụng của chúng. Ngoài các lĩnh vực hành chính của chính phủ nơi tiếng Anh được sử dụng rộng rãi, tiếng Anh cũng dần lan tỏa, thấm sâu vào môi trường xã hội, gia đình và cá nhân.

Thư hai, chính sách song ngữ được thực hiện làm giảm đáng kể số lượng người nói tiếng địa phương ở Singapore. Minh chứng cho vấn đề này là việc sử dụng tiếng Hán phương ngữ ở nhà đã giảm, trong khi các hộ gia đình tộc người gốc Hoa sử dụng tiếng phổ thông Hán ngữ làm ngôn ngữ thay thế phương ngũ Hán tăng. Nhìn chung, tỷ lệ những người nói tiếng Hán phương ngữ giảm mạnh và bị giới hạn chủ yếu cho người cao tuổi, còn tiếng Hán phương ngữ trở thành ngôn ngữ được lựa chọn ưu tiên, đặc biệt đối với người trẻ Singapore khi giao tiếp trong chính cộng đồng của họ ở khắp nơi.

Uu điểm lớn nhất trong việc thực hiện chính sách ngôn ngữ của Singapore là người dân của quốc gia này có thể nói ít nhất hai ngôn ngữ là tiếng Anh và tiếng mẹ đẻ. Đây được xem là chính sách khôn ngoan của chính phủ khi áp dụng vào Singapore, giúp người dân có thể tiếp cận các vấn đề toàn cầu được nhanh chóng, nhưng cũng không vì thế mà làm mất đi bản sắc dân tộc.

Xác nhận tiếng Anh là ngôn ngữ hành chính của đất nước, sử dụng tiếng Anh trong vai trò là ngôn ngữ làm việc, giúp hạn chế những khác biệt, giải quyết mâu thuẫn giữa các sắc tộc, ngăn chặn xung đột nảy sinh giữa các sắc tộc với nhau, xóa bỏ sự ngăn cách sắc tộc trong các trường học, góp phần tạo nên sự thống nhất quốc gia, ổn định xã hội. Bởi vậy, chính sách này không chỉ mang tính chất chuyên môn mà còn có ý nghĩa chính trị đặc biệt.

Hơn thế, tiếng Anh là công cụ để kết nối Singapore với thế giới trên mọi lĩnh vực, đem lại cho Singapore ưu thế cạnh tranh. Vì tiếng Anh là ngôn ngữ giao dịch, đàm phán và là ngôn ngữ của khoa học, kỹ thuật quốc tế, giúp Singapore nhanh chóng hội nhập với thế giới. Chính vì thế, việc thực hiện chính sách song ngữ, đẩy mạnh vị thế của tiếng Anh được khẳng định góp phần quan trọng vào sự thành công về kinh tế của đất nước và giúp Singapore trở thành một trung tâm giáo dục toàn cầu, là điểm đến của nhiều du hoc sinh trên thế giới.
3. Những vấn đề đặt ra trong quá trình thực hiện chính sách ngôn ngữ và giải pháp của chính phủ Singapore

\subsection{Nhũng tồn tại và các vấn đề tiềm ẩn trong chính sách song ngũ}

Thư nhất, chính phủ ủng hộ tiếng Anh với vai trò là ngôn ngữ chung giữa các chủng tộc nhưng lại phủ nhận tính đa dạng của nó, tức là không chấp nhận tiếng Anh "bồi" (Singlish) tồn tại trong thực tế xã hội. Những người ủng hộ tiếng Singlish cho rằng, tính bình dân của nó giúp xây dựng đoàn kết dân tộc - đạt được một trong những mục tiêu chính phủ đặt ra; trong khi đó, chính phủ phản đối tiếng Singlish bởi tính sai lạc của nó so với tiêu chuẩn hóa ngôn ngữ từ phía chính phủ.

Thư hai, chính sách song ngữ đặt ra yêu cầu quá mức cho học sinh trung bình. Hầu hết các học sinh phải học hai ngoại ngữ ở cấp tiểu học. Những người nói tiếng Hán phương ngữ mà không phải tiếng phổ thông Hán ngữ, phàn nàn rằng con cái của họ phải học hai ngoại ngữ - tiếng Anh và tiếng phổ thông Hán ngữ. Điều này trái ngược với chính sách sử dụng tiếng Anh và tiếng mẹ đẻ của họ. Họ nhấn mạnh vào việc dùng tiếng phổ thông Hán ngữ sẽ làm ảnh hưởng mối quan hệ gia đình, vì các thế hệ lớn tuổi thường không thông thạo tiếng phổ thông Hán ngữ (trừ khi đó là tiếng mẹ đẻ của họ).

Tương tự, theo chính sách song ngữ, người Singapore gốc Ân Độ chỉ có thể lựa chọn sử dụng tiếng Tamil làm tiếng mẹ đẻ của họ, các sinh viên không phải là người Tamil gốc Ấn Độ do đó đã gặp bất lợi. Mặt khác, sự gia tăng số lượng người nói tiếng Anh trong bối cảnh tiếng Anh chiếm ưu thế đã dẫn đến một tỷ lệ lớn ngôn ngữ của người Mã Lai bị pha tạp với tiếng Anh.

Thứ $b a$, chính phủ công nhận tầm quan trọng của tiếng Anh trong xã hội đa tộc người, tiếng Anh có ích trong việc đạt được sự gắn kết quốc gia giữa các tộc người và đem lại cho Singapore ưu thế cạnh tranh trong sự phát triển kinh tế toàn cầu, do đó nó được cho là có vị thế ngôn ngữ chính thức cao hơn. Trong khi đó, tiếng phổ thông Hán ngữ, Melayu, Tamil - dù cũng là ngôn ngữ chính thức của Singapore nhưng lại có vị thế kém hơn. Mặt khác, quá trình toàn cầu hóa đã và đang gây áp lực ngày càng gia tăng, buộc người dân phải hội nhập vào tiếng Anh và cái giá phải trả là sự suy vong tiếng mẹ đẻ của họ. 
3.2. Một số giải pháp của chính phủ Singapore nhằm giải quyết nhũng hạn chế đặt ra trong quá trình thục hiện chính sách ngôn ngũ

Nhiều sửa đổi đã được thực hiện để cho phép hệ thống giáo dục linh hoạt hơn và để phục vụ cho nhu cầu đa dạng ngôn ngữ ${ }^{19}$ :

• Những học sinh không đáp ứng được yêu cầu của giáo dục song ngữ có thể chọn để tập trung vào một ngôn ngữ, tức là tiếng Anh.

- Những học sinh có năng khiếu trong học tập ngôn ngữ, đáp ứng tốt yêu cầu của giáo dục song ngữ được khuyến khích học ngôn ngữ thứ ba, ngoài tiếng Anh và tiếng mẹ đẻ của họ.

Năm 1997, trước những khó khăn trong việc học tiếng mẹ đẻ của trẻ em gốc Trung Quốc từ các gia đình nói tiếng Anh, Ủy ban đánh giá tiếng phổ thông Hán ngữ được thành lập để nghiên cứu vấn đề. Ủy ban phát hiện ra rằng, chương trình trong sách giáo khoa quá khó đối với một số học sinh, từ đó đưa ra sự thay đổi như cung cấp chương trình học trình độ "B" tiếng phổ thông Hán ngữ vào năm 2001. Chương trình này được giảng dạy ở mức thấp hơn giúp học sinh gặp khó khăn trong tiếng phổ thông Hán ngữ có thể đạt được ngôn ngữ ở trình độ thông thạo khẩu ngữ. Năm 1999, Ban chỉ đạo về ngôn ngữ Melayu và Tamil cũng được thành lập. Từ các bài đánh giá về việc học và sử dụng ngôn ngữ Melayu, Tamil, Ban chỉ đạo đã giới thiệu chương trình học trình độ "B" cho hai ngôn ngữ đó. Thêm vào đó, chương trình và cơ sở giảng dạy tiếng Melayu và Tamil cao cấp cũng được phát triển.

Năm $2004^{20}$, Bộ giáo dục Singapore cũng có một số thay đổi đối với chính sách tiếng mẹ đẻ, thông báo mở "Chương trình học song ngữ" dành cho thiểu số sinh viên Singapore gốc Trung Quốc gặp vấn đề với cả tiếng Anh và tiếng phổ thông Hán ngữ ở trình độ bậc cao. Chính phủ cũng tuyên bố sẽ cân nhắc chương trình học bằng cả tiếng Tamil và tiếng Melayu để xem phương pháp áp dụng có giống với chương trình cho tiếng phổ thông Hán ngữ hay không. Chương trình giảng dạy này có thể đáp ứng các nhu cầu đa dạng của sinh viên và họ có thể tối đa hóa khả năng ngôn ngữ của mình.

\footnotetext{
${ }^{19}$ Goh, K. S. et al. (1979), Report on the Ministry of Education 1978, Singapore: Ministry of Education

${ }^{20}$ Lim, L., A. Pakir \& L. Wee (2010), Ed., English in Singapore: Modernity and Management, Singapore: NUS Press, pp. 9.
}

\section{Kết luận}

Chính sách ngôn ngũ̃ của Singapore rõ ràng đã thành công, đáp ứng mục tiêu đặt ra của chính phủ. Tiếng Anh dần trở nên phổ biến trong xã hội Singapore, bởi giờ đây tiếng Anh là phương tiện giảng dạy trong các trường học và nhân tố quan trọng trong hệ thống ngôn ngữ Singapore. Tuy nhiên, vẫn còn những vấn đề tồn tại trong chính sách song ngữ. Sự đa dạng ngôn ngữ tạo ra các mối đe dọa tiềm ẩn đối với công cuộc toàn cầu hoá và Singapore cần phải rất thận trọng trong giải quyết các tình huống xung đột ngôn ngữ và tộc người, nhằm bảo vệ tiếng phổ thông Hán ngữ, Melayu và Tamil, thậm chí là tiếng Hindi, Punjabi, Gujarati và Urdu cùng với tiếng Anh.

\section{TÀI LIỆU THAM KHẢO}

1. Census of Population 2010 Statistical Release 1: Demographic Characteristics, Education, Language and Religion (PDF). Department of Statistics, Ministry of Trade \& Industry, Republic of Singapore. January 2011. ISBN 978-981-08-7808-5. Archived from the original (PDF) on 3 March 2011. Retrieved 28 August 2011.17;

2. Clammer, John (1998), Race and State in Independent Singapore 1965-1990, Aldershot, England ; Brookfield, Vt. : Ashgate, c1998;

3. Deterding, David (1998) 'Approaches to Diglossia in the Classroom: The Middle Way. REACT, 2, 18-23.' (on-line version), http://www.mda.gov.sg/wms.file/mobj/mobj.612.fta_t v_prog_code.pdf

4. General Household Survey 2015, https://www.statssa.gov.za/publications/P0318/P0318 2015.pdf, truy cập 09 June 2018;

5. Goh, K. S. et al. (1979), Report on the Ministry of Education 1978. Singapore: Ministry of Education;

6. Kaplan B., Robert, and Richard B. Baldauf Jr (1997), Language Planning from Practice to Theory.Clevedon: Multilingual Matters ltd;

7. Foley, Joseph (2001) "Is English a first or second language in Singapore?", in Vincent B. Y. Ooi (ed.), Evolving Identities: The English Language in Singapore and Malaysia, Singapore: Times Academic Press, pp. 12-32;

8. Leimgruber, Jakob, From Post-Creole Continuum to Diglossia: The Case of Singapore English (PDF), University of Oxford; 
9. Lim, L., A. Pakir \& L. Wee (2010), Ed., English in Singapore: Modernity and Management, Singapore: NUS Press, pp. 9;

10. Lionel Wee (2010), Burdens' and 'handicaps' in Singapore Language Policy: on the limits of language management', Language Policy, Volume 9, Issue 2;

11. Mohamed, S. (2005) Planning for Malay Language in Education, Centre for Research in Pedagogy and Practice, Nanyang Institute of Education, Singapore;

12. "Singapore attack on 'Singlish", BBC News. 5 April 2001. Retrieved 13 November2011;
13. Speak Good English Movement - What We Do Archived 30 August 2011 at the Wayback Machine. Retrieved 18 November 2010;

14. Tien, Adrian (2010), Chinese-based lexicon in Singapore English, and Singapore-Chinese culture (PDF), archived on 27 November 2010, http://old.nbu.bg/PUBLIC/IMAGES/File/departamenti/4 ujdi\%20ezitsi\%20i\%20literaturi/Doklad_Adrien_2.pdf;

15. Vasil, Raj (1995), Asianing Singapore: The PAP's Management of Ethnicity, Singapore: Heinemann Asia;

16

Worldometer 2017 , http://www.worldometers.info/worldpopulation/singapore-population/ truy cập ngày 04/2/2018.

\section{Singapore's language policies}

Nguyen Thi Nhu

\section{Article info}

Recieved:

18/03/2018

Accepted:

$12 / 6 / 2018$

Keywords:

Singapore, language policies, solutions.

\begin{abstract}
Singapore is a multi-lingual country, thus the language policy attachs to its government plans. Currently, the Singapore government maintains linguistic diversity, affecting the use of languages and corresponding their functions in the communities that speak those languages through the education system. The paper attentively introduces, overviews Singapore's language policy and clarifies 03 issues: (1). Singapore linguistic diversity and policy toward languages; (2). Principle issues about Singapore's language policies; (3). Issues raised during the implementation of Singapore's policies and solutions.
\end{abstract}

